\title{
Mandibular solitary plasmocytoma of the jaw: A case report
}

\author{
Beatriz Rodríguez-Caballero ${ }^{1}$, Sergio Sanchez-Santolino ${ }^{1}$, Belén García-Montesinos-Perea ${ }^{1}$, Maria-Fe Gar- \\ cia-Reija ${ }^{1}$, Javier Gómez-Román ${ }^{2}$, Ramon Saiz-Bustillo ${ }^{3}$
}

${ }^{1}$ Oral and Maxillofacial Surgeon, University Hospital "Marqués de Valdecilla" (Santander, Cantabria, Spain)

${ }^{2}$ Medical Pathologyst, University Hospital "Marqués de Valdecilla" (Santander, Cantabria, Spain)

${ }^{3}$ Chief of Oral and Maxillofacial Surgery, University Hospital "Marqués de Valdecilla" (Santander, Cantabria, Spain)

Correspondence:

Avda. Oviedo $N^{\circ} 9$ Edif 2 Bj B,

CP 39710Solares (Cantabria, Spain)

beroca8@yahoo.es

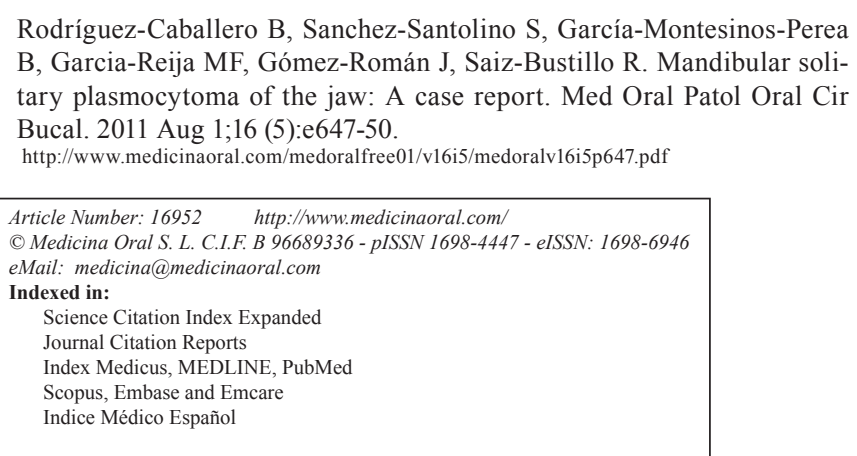

\begin{abstract}
Plasma cell tumors are lymphoid neoplasms with an uncontrolled proliferation of B cells. These are divided into localized forms (solitary bone plasmocytoma -SBP- and extramedullary plasmocytoma -EP-) and disseminated forms (multiple myeloma-MM-). The SBP is a rare and controversial disease. The aim of this article is the analysis of this entity based on the presentation of a 64-year-old man without previous medical history, with a mass in the left mandibular angle extending to the parotid region on the same side. The panoramic radiography, computed tomography and magnetic resonance imaging showed an osteolytic lesion $6.5 \times 5 \times 6.7 \mathrm{~cm}$ in the mandibular angle with infiltration of the masticator space and left parotid region. The normality of the extension study, and histopathological examination confirmed the diagnosis of SBP. The patient received treatment with radiotherapy with good outcome.
\end{abstract}

Key words: Mandibular tumors, plasma cell neoplasms, solitary bone plasmocytoma.

\section{Introduction}

Plasma cell neoplasms are a group of clinical disorders characterized by an uncontrolled monoclonal proliferation of plasma cells or plasma cells derived (stem cells and lymphoid cell line B) and, in the case of multiple myeloma, by monoclonal overproduction of immunoglobulins in blood and / or detecting light chains in the urine as Bence Jones protein (1-3). The incidence of these tumors is about 2,6-3,3 per 100,000 population being higher in blacks. The average age of presentation is in the sixth decade of life (2). Localized forms of plasma cells neoplasms are solitary bone plasmacytoma (SBP) and extramedullary plasmocytoma (EMP), multiple myeloma (MM) is the disseminated type of this disorder (1-5). In the maxillofacial area plasmocytoma may be divided into different clinical forms: a manifestation of disseminated disease (MM), a solitary lesion in the soft tissues (often in the parotid gland) or a solitary bone lesion with or without invasion of local structures (as in the case presented) (6-8). 
The biological behaviour of these tumors is variable, from periods of clinical latency to rapid growth and progression from the localized forms (SBP and EMP) to (MM). EMP has a better prognosis because $30 \%$ progress to MM compared with $70 \%$ in SBP $(1,2,5)$. Many authors have considered SBP as an early manifestation of MM. This article presents a brief general discus of head and neck manifestations of plasma cell neoplasms.

\section{Case Report}

A 64-year-old male consulted the Department of Oral and Maxillofacial Surgery, University Hospital Marqués de Valdecilla (Santander) in January 2008 with the primary complaint of a painless swelling in the left preauricular region that he had first noticed 1 month before. The patient's surgical history included removal of a remnant root in his left lower jaw two weeks before. The physical examination showed a firm, no mobile mass measuring approximately $5 \mathrm{~cm}$ in its greatest dimension in the left preauricular region to the mandibular angle. Neurologic examination of cranial nerves $\mathrm{V}$ and VII was normal without visible skin changes. The oral examination showed a slight bulging on the mandibular angle covered with normal oral mucosa. The mouth opening pattern was $4.5 \mathrm{~cm}$. without laterodeviation and / or clicking on the left temporomandibular joint (Fig. 1).

Panoramic radiography showed an ill-defined, multilocular, radiolucent mass in the left mandibular angle and ramus. Ultrasound of salivary glands revealed on the superficial lobe of left parotid gland a lesion, $5,8 \mathrm{~cm}$ in its greatest diameter, with peripheral desmoplastric reaction. Doppler study were performed demonstrated no significant increase in vascularization. The Computerized Tomography (CT) and Magnetic Resonance
(MRI) showed a $6.5 \times 5 \times 6.7 \mathrm{~cm}$. destructive mass that extended from the posterior third of the mandibular body to the ramus with infiltration of the masticatory space and parotid gland (Figs $2 \mathrm{~A}$ and $\mathrm{B}$ ).

Aspiration cytology was not conclusive, so an incisional biopsy was performed under general anesthesia. The histology confirmed the diagnosis of CD 138 + bone plasmacytoma with kappa light chain restriction (Fig. 3).

The patient was them referred to haematology department. A skeletal radiographic survey was obtained and showed no other osteolytic lesions. Laboratory analysis of the patient's blood and urine revealed no monoclonal gammopathy or Bence Jones protein.

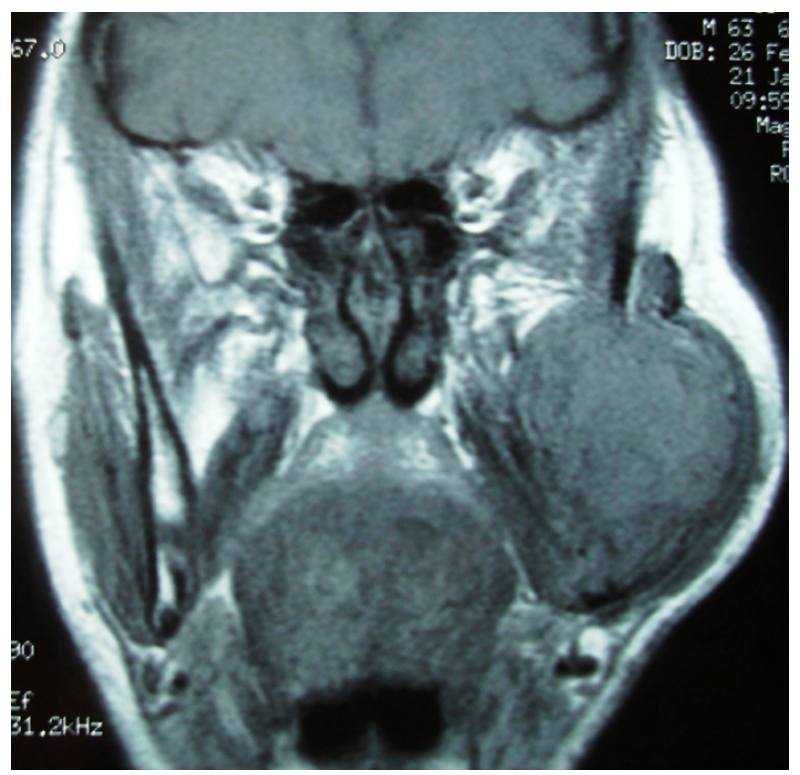

Fig. 2A. MRI coronal section.

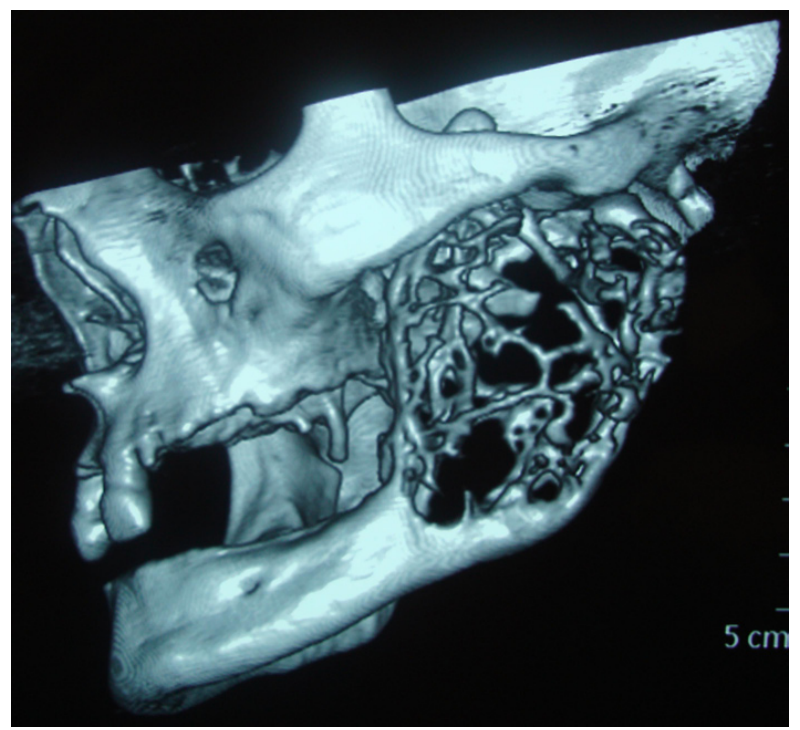

Fig. 2B. 3D CT.
Fig. 1. Tumor extending from left mandibular angle to the parotid region. 


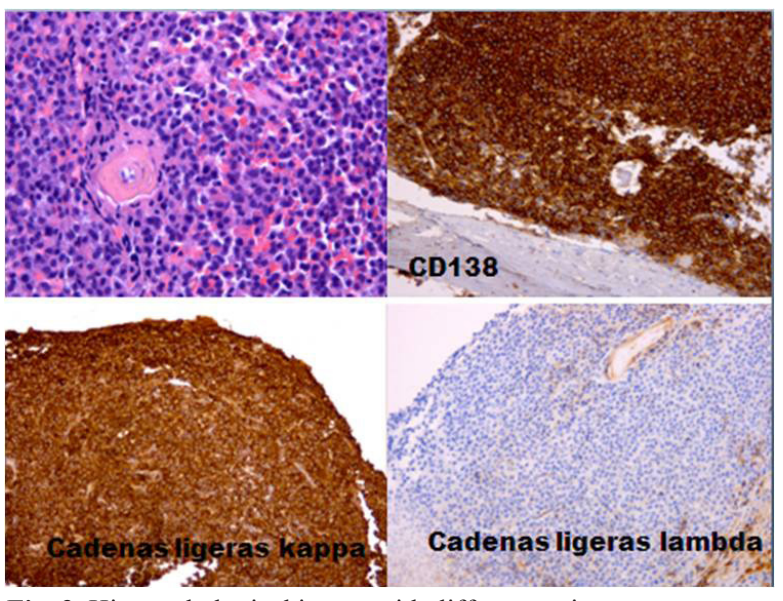

Fig. 3. Histopathological image with different stains.

The results of medulogram confirmed a $3 \%$ atypical plasma cells. The skeletal survey as well as laboratory investigations confirmed the diagnosis of solitary bone plasmacytoma. The patient was treated with local radiotherapy to a dose of $45 \mathrm{~Gy}$, with good outcome. One year after finishing the treatment the patient is asymptomatic and without signs of recurrence.

\section{Discussion}

Solitary bone plasmacytoma is a localized malignant monoclonal gammopathy which constitutes approximately $3-10 \%$ of all plasma cell tumours $(1,2)$. The peak incidence is in the sixth decade of life, being more prevalent in male than females with a ratio 2:1(1). The most common sites of SBP are the vertebrae, long bones and skull. It is rarely involved the maxillofacial area most commonly in the mandible, especially in the bone marrow-rich areas: the retromolar trigone, angle and ramus (4.5). Local clinical signs and symptoms are bone swelling, localized pain in the jaws and teeth, numbness and / or anesthesia, bleeding, tooth mobility and possible bone fracture. Involvement of local mucosa or tissues, as in our case, it can also be seen. Fatigue or fever are the most common systemic symptoms (5-7). Radiographically SBP is seen as a well defined uni or multilocular lytic lesion without periosteal reaction (4), or as a protruding mass with cortical expansion (6).CT, MRI and more recently PET, are useful to establish the characteristics of the lesion and tissues involved and to rule out other affected areas $(4,7)$.

Diagnosis is based on the presence of malignant proliferation of plasma cells in the biopsy, absence of further osteolytic bone lesions (mainly, in the iliac crest and sternum), histologically normal marrow aspirate and absence or low concentrations of serum or urine monoclonal protein. The last criterion to confirm the diagnosis is the histopathological analysis of the affected bone (2). Histological features of SBP are sheets or clusters of atypical plasma cells with various types of differentiation. These cells may present as mature plasma cells of normal spectrum or different degrees of maturity, from undifferentiated cells similar to lymphoid precursors (plasmacytoma) to intermediate forms between lymphocytes and plasma cells. There are three different groups of differentiation, which are related to the rate of survival: 1) low dysplasia, with less than $10 \%$ of plasmoblastos 2) moderate dysplasia, with $10-50 \%$ of plasmoblastos, and 3) severe dysplasia with $50 \%$ of immature forms and worse prognosis than the others. These cells are round or oval with excentric nuclei, chromatin pattern "cartwheel" and acidophilic inclusions known as "Russell bodies" $(5,8,9)$.

The primary treatment of SBP is radiation therapy, radical extensive surgery, or both combined $(8,10)$. Radical radiotherapy is the treatment of choice at doses of 40-50 Gy, showing an index of local disease control of $80 \%$. There is no evedence of relationship for a 40-45 Gy dose response and tumor size (11). Surgical treatment is elective in those selected cases where all tumour is removed with minimal cosmetic or functional deficit or those to prevent or stabilize a pathologic mandibular fracture. The partial resection, with or without adjuvant radiotherapy, has not been shown to decrease survival or local control compared to radiotherapy treatment isolated.

The role of adjuvant chemotherapy is at present not clearly defined. The addition of chemotherapy to radiotherapy in the treatment of SBP has not been shown to decrease local recurrence or increase survival rates compared to local treatment with radiotherapy alone, therefore, should be reserved for those cases progressing to multiple myeloma $(12,13)$.

Currently, there is considerable interest in the role of angiogenesis inhibitors, thalidomide, protease inhibitors or inhibitors of vascular endothelium growth factor in plasma cell neoplasms, which could, in a future, be an alternative treatment (14).

Between 35 and $85 \%$ of SBP progress to MM arising in a period of few months to years after diagnosis, in fact, some authors consider the SBP an early stage of the disseminated disease. It is not possible to predict which case may transform although there are some risk factors: age ( $>60$ years), M component levels $>20 \mathrm{~g} /$ $\mathrm{L}$ up to one year following radiotherapy, large tumour neovascularization and tumor size $>5 \mathrm{~cm}$ (this more discussed) $(14,15)$. So after treatment, SPB cases must be closely followed up $(1,2,5)$.

The course of SPB is relatively benign and survival is $50-80 \%$ at 10 years. The prognosis of solitary plasmacytoma is worse if recurrence is present as in cases of evolution toward systemic disease and survival at 10 years is $16 \%$ and the average outliving is over $60-90$ months $(1,10-13)$. 


\section{Conclusions}

1. Solitary bone plasmacytoma is a localized form of plasma cell tumours. Maxillofacial area it is rarely affected, most commonly the mandible.

2. This entity requires a meticulous overview of the patient by the specialist and overall the control of any signs or symptoms of systemic diseases, a fact that would mark a dramatic change in the treatment and prognosis of the patient.

3. Treatment includes radiation therapy, radical extensive surgery, or both combined. Chemotherapy should be reserved for those cases progressing to multiple myeloma.

4. The course of SPB is relatively benign and survival is $50-80 \%$ at 10 years. The prognosis is worse if recurrence is present as in cases of evolution toward systemic disease.

\section{References}

References with links to Crossref - DOI

1. Canger EM, Celenk P, Alkan A, Günhan O. Mandibular involvement of solitary plasmocytoma: a case report. Med Oral Patol Oral Cir Bucal. 2007;12:E7-9.

2. Seoane J, Aguirre-Urizar JM, Esparza-Gómez G, Suárez-Cunqueiro M, Campos-Trapero J, Pomareda M. The spectrum of plasma cell neoplasia in oral pathology. Med Oral. 2003;8:269-80.

3. Pinto LS, Campagnoli EB, Leon JE, Lopes MA, Jorge J. Maxillary lesion presenting as a first sign of multiple myeloma: case report. Med Oral Patol Oral Cir Bucal. 2007;12:E344-7.

4. Matsumura S, Kishino M, Ishida T, Furukawa S. Radiographic findings for solitary plasmacytoma of the bone in the anterior wall of the maxillary sinus: A case report. Oral Surg Oral Med Oral Pathol Oral Radiol Endod. 2000;89:651-7.

5. Pisano JJ, Coupland R, Chen SY, Miller AS. Plasmacytoma of the oral cavity and jaws: a clinicopathologic study of 13 cases. Oral Surg Oral Med Oral Pathol Oral Radiol Endod. 1997;83:265-71.

6. Poggio CE. Plasmacytoma of the mandible associated with a dental implant failure: a clinical report. Clin Oral Implants Res. 2007;18:540-3.

7. Ozdemir R, Kayiran O, Oruc M, Karaaslan O, Koçer U, Ogun D. Plasmacytoma of the hard palate. J Craniofac Surg. 2005;16:164-9.

8. Furutani M, Ohnishi M, Tanaka Y. Mandibular involvement in patients with multiple myeloma. J Oral Maxillofac Surg. 1994;52:23-5. 9. Sukpanichnant S, Cousar JB, Leelasiri A, Graber SE, Greer JP, Collins RD. Diagnostic criteria and histologic grading in multiple myeloma: histologic and immunohistologic analysis of 176 cases with clinical correlation. Hum Pathol. 1994;25:308-18.

10. Chao MW, Gibbs P, Wirth A, Quong G, Guiney MJ, Liew KH. Radiotherapy in the management of solitary extramedullary plasmacytoma. Intern Med J. 2005;35:211-5.

11. Dagan R, Morris CG, Kirwan J, Mendenhall WM. Solitary plasmacytoma. Am J Clin Oncol. 2009;32:612-7.

12. Mendenhall WM, Mendenhall CM, Mendenhall NP. Solitary plasmacytoma of bone and soft tissues. Am J Otolaryngol. 2003;24:395-9.

13. Elias HG, Scott J, Metheny L, Quereshy FA. Multiple myeloma presenting as mandibular ill-defined radiolucent lesion with numb chin syndrome: a case report. J Oral Maxillofac Surg. 2009;67:1991-6.

14. Knobel D, Zouhair A, Tsang RW, Poortmans P, Belkacémi Y, Bolla M, et al. Prognostic factors in solitary plasmacytoma of the bone: a multicenter Rare Cancer Network study. BMC Cancer. 2006;6:118. 15 . Kumar S. Solitary plasmacytoma: is radiation therapy sufficient? Am J Hematol. 2008;83:695-6. 